\title{
On the Construction of Substitutes
}

\author{
ERIC BALKANSKI, Harvard University \\ RENATO PAES LEME, Google Research
}

Gross substitutability is a central concept in Economics and is connected to important notions in Discrete Convex Analysis, Number Theory and the analysis of Greedy algorithms in Computer Science. Many different characterizations are known for this class, but providing a constructive description remains a major open problem. The construction problem asks how to construct all gross substitutes from a class of simpler functions using a set of operations. Since gross substitutes are a natural generalization of matroids to real-valued functions, matroid rank functions form a desirable such class of simpler functions.

Shioura proved that a rich class of gross substitutes can be expressed as sums of matroid rank functions, but it is open whether all gross substitutes can be constructed this way. Our main result is a negative answer showing that some gross substitutes cannot be expressed as positive linear combinations of matroid rank functions. En route, we provide necessary and sufficient conditions for the sum to preserve substitutability, uncover a new operation preserving substitutability and fully describe all substitutes with at most 4 items.

Full Paper: https://arxiv.org/abs/1805.03726

CCS Concepts: • Applied computing $\rightarrow$ Electronic commerce; Economics;

Additional Key Words and Phrases: Gross substitutes; Matroids; Valuation functions.

Eric is supported by a Google PhD Fellowship.

Authors' addresses: Eric Balkanski, Harvard University, ericbalkanski@g.harvard.edu; Renato Paes Leme, Google Research, renatoppl@google.com.

Permission to make digital or hard copies of part or all of this work for personal or classroom use is granted without fee provided that copies are not made or distributed for profit or commercial advantage and that copies bear this notice and the full citation on the first page. Copyrights for third-party components of this work must be honored. For all other uses, contact the owner/author(s).

(C) 2018 Copyright held by the owner/author(s).

ACM EC'18, fune 18-22, 2018, Ithaca, NY, USA. ACM ISBN 978-1-4503-4529-3/18/06.

https://doi.org/10.1145/3219166.3219184 